\title{
Influence of Local Porosity on the Mechanical Properties of Direct Metal Laser-Sintered 1.2709 Alloy
}

\author{
István Hatos* - Imre Fekete - Dóra Harangozó - Hajnalka Hargitai \\ Széchenyi István University, Department of Materials Science and Technology, Hungary
}

Powder bed metal printing has demonstrated its potential for the direct manufacturing of complex parts. It has great flexibility compared to conventional manufacturing. There are also some difficulties and problems, e.g., because the process stops during production. When the process is restarted, the first layer may be thicker due to technological limitations. In this paper, the effects caused by the presence of these thicker layers were investigated. The possibility of re-melting the layers to reduce porosity were also analysed. A tool steel powder grade 1.2709 was used to produce samples with an increased thickness of melted layers.

Keywords: DMLS, SLM, porosity, layer thickness, mechanical properties, laser re-melting, 1.2709 steel

Highlights
- The effect of locally increased process stopping was investigated during direct metal laser sintering.
- $\quad$ Yield strength and tensile strength are not affected if layer thickness is slightly increased locally in the laser-sintered part.
- $\quad$ An increase in layer thickness decreases elongation at break and impact energy in a linear fashion.

\section{INTRODUCTION}

Since the first method for rapid prototyping (RP) appeared in the late 1980s, it has become one of the most rapidly developing manufacturing techniques in the world [1]. Layer-by-layer manufacturing processes have considerable benefits, such as time and cost savings, the possibility of producing nearly freeform geometries and less waste in comparison to traditional manufacturing processes [2]. Selective laser melting (SLM) and direct metal laser sintering (DMLS) are additive manufacturing (AM) technologies that use a high-power density focused laser beam to melt metallic particles together and create net-shaped metallic parts from 3D computer-aided design (CAD) models. In comparison to general conventional manufacturing technologies (e.g., turning, milling), laser processing typically does not require mechanical tooling. The technology enables the construction of advanced 3D parts for various applications, such as automobiles, aviation, medical supplies [3], mechanical parts [4] and tooling [5].

The complex microstructure of DMLS/SLM parts is different from conventional (cast/wrought) materials. The solidification texture is caused by the nature of the laser manufacturing (track-bytrack and layer-by-layer) process. Residual stresses can be attributed to high thermal gradients and thermocycling. In addition to chemical composition, mechanical properties also highly depend on the process parameters, e.g., laser power, building and scanning strategies, layer thickness, the protective atmosphere [6], and the flow of inert gas and the temperatures in the process chamber [7]. Non-optimal building parameters can cause inner defects, such as unmelted or partially melted powder particles, entrapped gas bubbles, cracks [8], inhomogeneous grain sizes and other types of local irregularities [9]. Problems during the process can result in the stopping of the machine, job failure, porosities or other defects. These imperfections will not always be visible. With a dedicated system, layer-by-layer building can be monitored throughout the entire process [10].

A number of papers deal with the topic of how layer thickness influences the mechanical properties of SLM/DMLS samples. Guan et al. [11] analysed the influence of layer thickness on the tensile properties of 304 stainless steel. The results of this research show that the tensile properties of SLM samples produced with layers in the $20 \mu \mathrm{m}$ to $40 \mu \mathrm{m}$ thickness range have negligible differences due to the similar metallurgical bonding and microstructures. Samples were fabricated with layer thicknesses of $30 \mu \mathrm{m}, 50 \mu \mathrm{m}$ and $70 \mu \mathrm{m}$ from $304 \mathrm{~L}$ powder. At the layer thickness of $70 \mu \mathrm{m}$, porosity increased significantly [12]. Yasa et al. [13] studied the microstructure and mechanical properties of 1.2709 alloy after SLM. The results show that in order to decrease the porosity, laser re-melting may be an easy solution which can be applied by laser rescanning each layer before depositing a new layer of powder. However, this will increase the production time; thus, it could be used in special applications. Mireles et al. [14] also found that laser re-melting could improve porosity; therefore, it could use as an 
in situ correction method. The manufacturing system can be instructed to re-scan the affected region once the defect is detected.

In the literature, several measuring methods are used to determine the porosity of additive manufactured parts, such as the density-based (Archimedes') method [15], plane porosity based on 2D image analysis [16], or the X-ray computed tomography (CT) 3D method [17] and [18]. Wits et al. [19] focused on the comparison of porosity testing methods for the quality assessment of selective laser melted parts. The experimental results showed that the results of Archimedes' method are comparable to the CT results. However, CT predicts systematically higher relative density for several reasons, including the different measuring method and the presence of unmolten powder residue. CT measures smaller values of porosity (percentage for volume) than microscopic methods.

In general, production parameters do not change during laser sintering; the parts are produced with uniform layer thickness. The production process sometimes needs to be interrupted due to lens cleaning, powder refilling, recoater collision, or other technical problems. Process restarting, different heights of hybrid parts, or build plate movements due to recoater collisions may cause a thicker layer being built.

Many scholars above have studied the influence of porosity on the quality of SLM/DMLS parts and proposed laser re-melting to improve porosity in certain regions. However, the effect of local re-melting on the performance of metal AM has not been studied in detail. According to the knowledge of the authors of the present paper, there is a lack of data in the literature concerning the influence of local porosity on the mechanical properties of 1.2709 maraging steel parts produced by DMLS.

In our previous research project [20], samples including layers of $20 \mu \mathrm{m}$ to $160 \mu \mathrm{m}$ thickness (in $20 \mu \mathrm{m}$ steps) were characterized. 1.2709 maraging steel powder was used, and we concluded that skipping one or two layers does not cause a measurable increase in porosity. We found that yield strength and tensile strength were not affected if layer thickness was only slightly increased. The results of Charpy impact tests are much more sensitive to increasing layer thickness; the lack of completely melted layers lowers absorbed energy (KV) significantly.

In the current research, specimens from a metal powder grade 1.2709 were manufactured with DMLS technology. In specific cross-sections of the specimens, one layer thickness was changed in the same range as in our previous work $(20 \mu \mathrm{m}$ to 160 $\mu \mathrm{m})$, then we investigated the effect of increased layer thickness and laser re-melting on porosity and mechanical properties.

\section{METHODS}

In this chapter, the materials, sample manufacturing and experimental methods are introduced.

\subsection{Materials and Sample Manufacturing}

The samples were prepared from Maraging Steel MS1 (1.2709) steel powder (supplied by EOS) by DMLS. The powder used for the specimens was reclaimed from prior jobs with the use of an $80 \mu \mathrm{m}$ sieve. An EOSINT M270 machine equipped with a $200 \mathrm{~W}$, $1070 \mathrm{~nm}$ laser was used with the EOS MS1_02_101 surface parameter setting and $20 \mu \mathrm{m}$ layer thickness in a nitrogen gas atmosphere.

Cubes of $\sim 5 \mathrm{~mm} \times 5 \mathrm{~mm} \times 5 \mathrm{~mm}$ were produced with higher layer thicknesses in some layers to quantify porosity caused by skipping the melting of certain layers. Layers with increasing thicknesses were printed with a spacing of $0.25 \mathrm{~mm}$ in the build direction. The layer thickness was increased in $20 \mu \mathrm{m}$ increments. Two cubes were prepared: one in which the increased thickness layer was melted once and another in which it was melted twice. Cylindrical $\varnothing 8 \mathrm{~mm}$ tensile test bars and $10 \mathrm{~mm} \times 10 \mathrm{~mm}$ Charpy impact specimens with a $\mathrm{V}$ notch were made with a different layer thickness in the middle layers of the specimens.

\subsection{Test Methods}

Tensile mechanical properties were tested according to the MSZ EN ISO 6892-1 standard method B [21] on an INSTRON 5582 testing machine. Charpy impact tests were performed on $\mathrm{V}$-notched specimens according to the MSZ EN ISO 148-1 standard [22] at room temperature.

The porosity of each cube sample was determined via the analysis of metallographic longitudinal crosssections parallel to the building direction (2D).

Prior to the microstructural examination, the samples were first ground with $\mathrm{SiC}$ grinding paper up to 360 grit size, then polished. A Zeiss Axioimager M1 optical microscope with a motorized platform was used to image the prepared specimens. The micrographs were automatically stitched and analysed by the Axiovision image processing software. 
The determination of the $2 \mathrm{D}$ porosity of the constant-sized regions was carried out with the following process. A grayscale image of the mosaic was created in order to make the material-void segmentation easier. The histogram of this image was used to determine a threshold value for the segmentation. This threshold value was chosen to separate the dark and light pixels (voids and material, respectively). After segmentation, the area of voids and the area of material were calculated. 2D porosity can be calculated as the ratio of void area to the total area.

Computed tomography scans were carried out with an YXLON Modular Y.CT system equipped with a $225 \mathrm{kV}$ micro-focus X-ray tube and a Y.XRD1260 flat panel detector. Tube voltage was $190 \mathrm{kV}$, and the tube current was $0.12 \mathrm{~mA}$. The flat panel detector was set to operate in a $2 \times 2$ binning mode with an integration time of $1000 \mathrm{~ms} ; 1440$ projections were taken with no filters used. The small size of the specimens allowed good magnification, yielding a voxel size of $8.23 \mu \mathrm{m}$. The resulting 10243 voxel data was loaded into VGStudio MAX for analysis. After the registration of the voxel dataset into a coordinate system, automated volumetric measurements were run to determine $3 \mathrm{D}$ porosity.

Similarly to $2 \mathrm{D}$ porosity, the histogram of the voxel array was used to segment the dark and light voxels (voids and material, respectively). After segmentation, the volume of voids and the volume of material were calculated. 3D porosity can be calculated as the ratio of void volume to the total volume.

\section{EXPERIMENTAL AND RESULTS}

\subsection{Comparison of the porosity testing methods}

Locally increased layer thickness reduces the heat concentration and causes an increase in local porosity as a result of insufficient melting of the deposited powder, while the porosity of unaffected areas is constant. Fig. 1 shows the effect of $160 \mu \mathrm{m}$ layer thickness. It can be seen that large structures (coarse grains) are created differed largely from those of below and above, which were formed during uniform melting. The material structure is non-continuous, because the laser energy cannot melt the metal powder completely and significant porosity remains in the area of scanning boundaries.

For the quantification of local porosity, the measurement area must be defined around the skipped layers (Fig. 2).

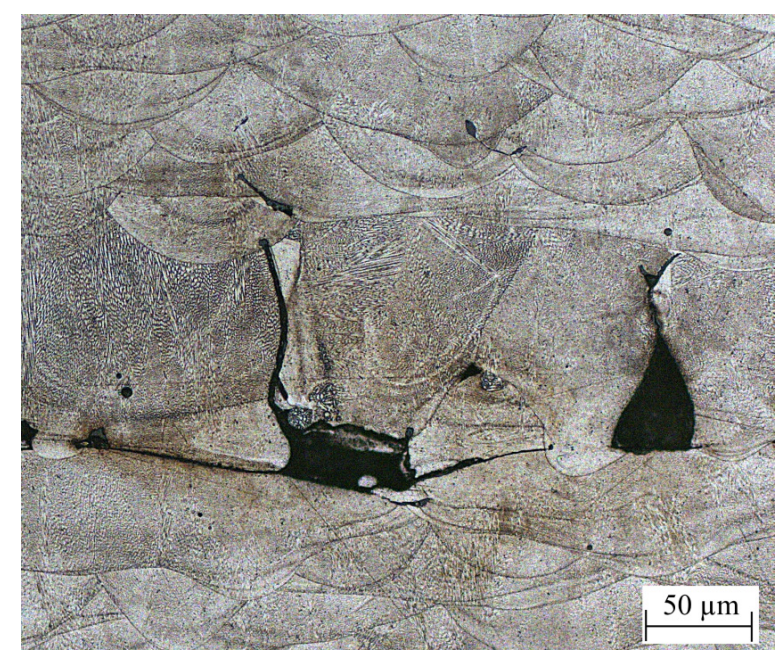

Fig. 1. Microstructure of the polished cross-section containing $160 \mu \mathrm{m}$ layer thickness

width of porosity Detect

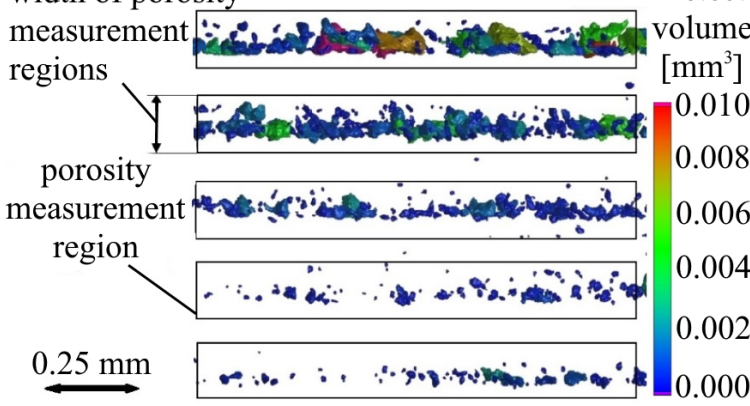

Fig. 2. CT image of the laser-sintered part (cube) containing layers with different thicknesses (from bottom to top: (80, 100, 120, 140 and160) $\mu \mathrm{m})$ ) with the porosity measurement regions defined

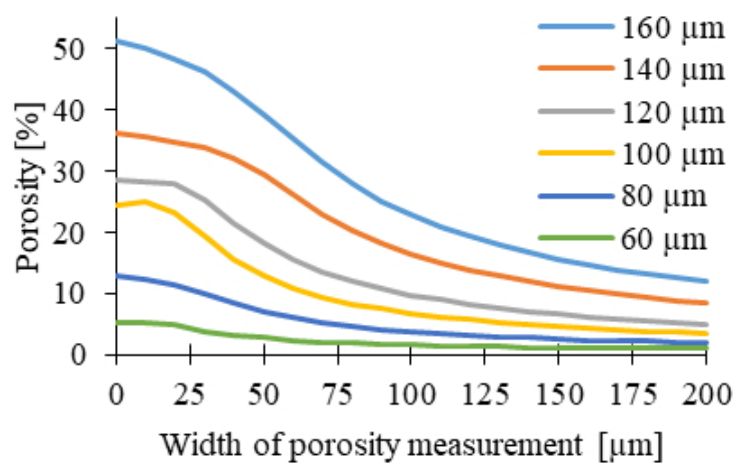

Fig. 3. Measured porosity for parts printed with increasing layer thickness (60 $\mu \mathrm{m}$ to $160 \mu \mathrm{m})$ as a function of the width of the measuring rectangle

To compare $2 \mathrm{D}$ and $3 \mathrm{D}$ porosity measurements, we determined porosity by both methods on a reference part. The results of the methods are in good agreement, which proves that both are capable of measuring local porosity in DMLS samples. However, 
CT results are influenced by several technical limitations (e.g., pores smaller than the resolution). Therefore, the density determined by CT can be different from the density measured by microscopy analysis.

The porosity percentages were determined as the ratio of the area/volume of the voids to the total area/ volume of the region of interest. The total measured area/volume can greatly influence the results. Fig. 3 shows that as the width of the measuring rectangle in 2D measurement increases, calculated porosity decreases for the given area.

It can be stated that the size of the measurement region significantly affects the measured porosity of the layer.

\subsection{Porosity}

Fig. 4 shows the effect of locally increased thickness $(120 \mu \mathrm{m}$ to $160 \mu \mathrm{m})$. The outer surface of the specimens shows that higher increases in layer thickness can be observed with the naked eye. The results indicated that 1-2 skipped layers built with standard building parameters will not cause visible defects.

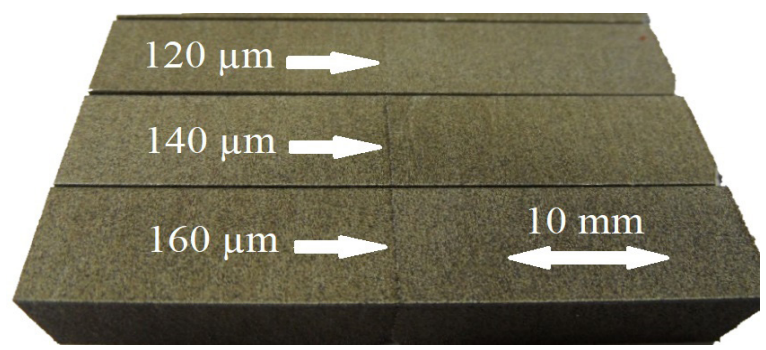

Fig. 4. Image of the outer surface of samples containing a thicker layer $(120 \mu \mathrm{m}$ to $160 \mu \mathrm{m})$

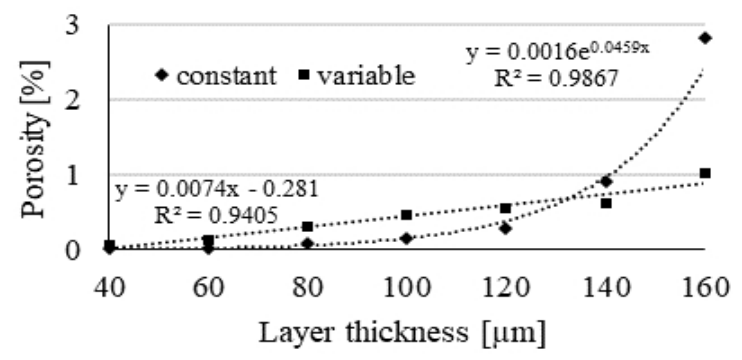

Fig. 5. Porosity as a function of layer thickness in case of using constant and variable size of the analysed region

In the case of the locally increased thicknesses, the size of the porosity measurement region affects the measured porosity. Porosity was measured with the use of equal-size regions $(220 \mu \mathrm{m})$ and regions of a size proportional to the thickness of the increased layer ((layer thickness; $20 \mu \mathrm{m}) \times 2$ ). Fig. 5 shows that with a constant measurement region, porosity rises sharply at high layer thicknesses. When the size of the analysed region for porosity changes (in the $40 \mu \mathrm{m}$ to $320 \mu \mathrm{m}$ range), the porosity percentage changes in a linear fashion as a function of layer thickness. (Fig. 5).

\subsection{Mechanical Properties}

Tensile tests were carried out at room temperature with a non-contact video extensometer to measure strain. We tested three specimens for each modified layer thickness and determined yield strength, tensile strength, and the percentage elongation after fracture $\left(\mathrm{A}_{40}\right)$ from the stress-strain curves.

As mentioned before, yield strength and tensile strength are not affected if layer thickness is slightly increased locally in the laser-sintered part. A significant decrease in yield strength and tensile strength was found when the $160 \mu \mathrm{m}$ layer was melted in one step. In this case, the specimen displayed brittle behaviour; it broke without any plastic deformation in the elastic region. Building load-bearing parts with layer thickness locally increased to this value is not recommended. Thus, the results are only presented up to a layer thickness of $140 \mu \mathrm{m}$.

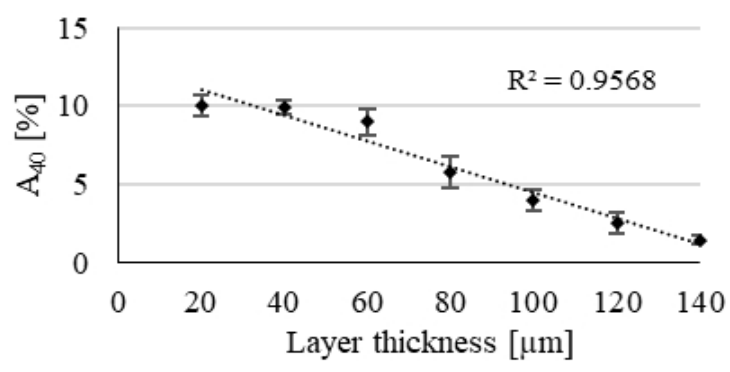

Fig. 6. Elongation $\left(\mathrm{A}_{40}\right)$ as a function of layer thickness

Elongation, as a function of layer thickness, can be seen in Fig. 6. There is a well-defined correlation between layer thickness and elongation values. As layer thickness increases, elongation decreases linearly. This phenomenon can be explained by the failure mechanism of ductile materials, which is starting with the void nucleation followed by growing with increasing hydrostatic stress and local plastic straining and then coalescence. The porosity in low concentration does not result in a measurable loss of stiffness or yield strength and tensile strength but does reduce the ductility since microvoids exist before any stress is applied. The same phenomenon was found by Hardin and Beckermann [23] in the case of cast iron. 
The $10 \mathrm{~mm} \times 10 \mathrm{~mm}$ cross-section V-notched Charpy test specimens were tested at room temperature. The increased layer thickness was created in the centreline of the V-notch. As expected, increasing porosity resulted in less ductility (Fig. 7).

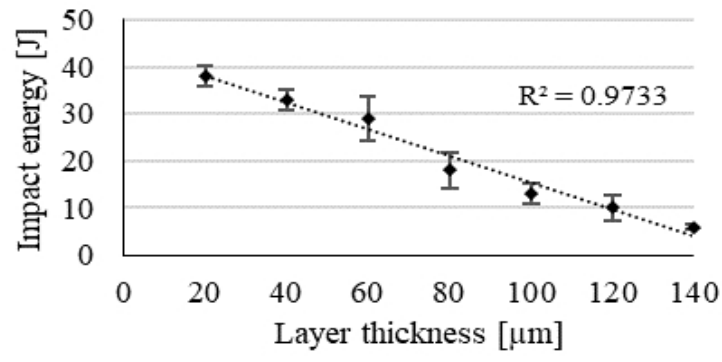

Fig. 7. Impact energy as a function of layer thickness

The energy absorbed by the specimens during fracture and the elongation $\left(\mathrm{A}_{40}\right)$ shows a similar correlation with layer thickness, which can be explained with the above-described phenomena due to the increasing porosity.

Fig. 8 shows that impact energy linearly increases as a function of elongation at break.

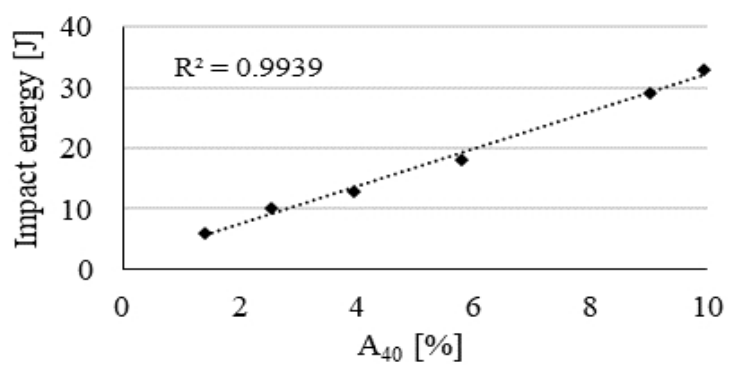

Fig. 8. Impact energy as a function of elongation $\left(\mathrm{A}_{40}\right)$

For further investigation, fracture surfaces of the Charpy specimens with uniform $20 \mu \mathrm{m}$ layer thickness and containing $160 \mu \mathrm{m}$ layer were studied with a scanning electron microscope. Samples containing a $160 \mu \mathrm{m}$ thick layer in the middle showed brittlelike behaviour with no visible plastic deformation, although the SEM image shows that there are mostly ductile regions on the broken surface (Fig. 9b). The low ductility resulted in low elongation and low impact energy, which can be explained by the lack of fusion and visible cracks on the fracture surface which could act as stress concentrators.

The big holes with some powder particles (indicated with the arrows) prove the inadequate melting during the process.
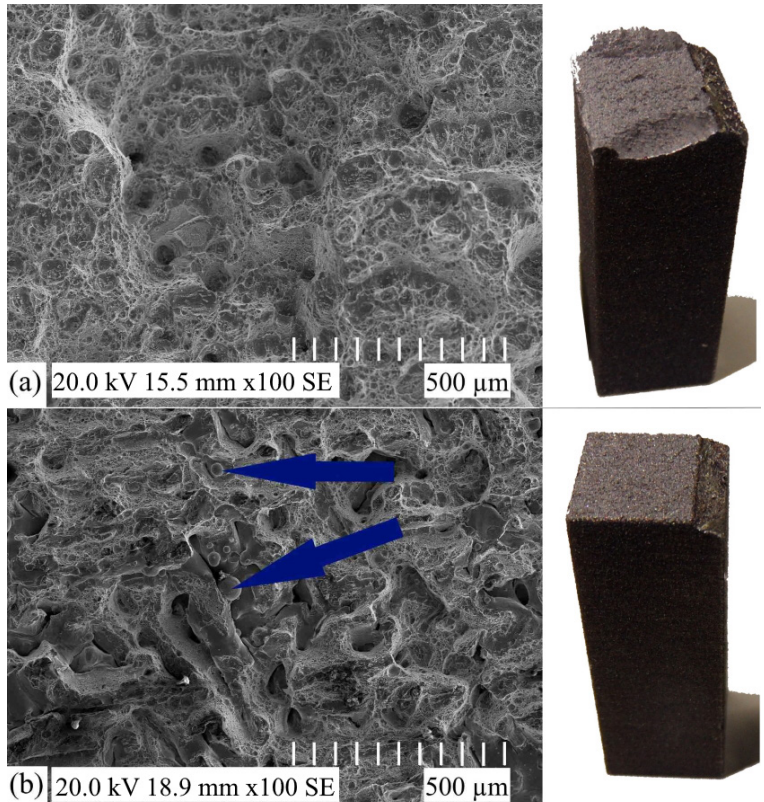

Fig. 9. SEM image of fracture surface of Charpy specimens a) uniform $20 \mu \mathrm{m}$ layer thickness and b) containing $160 \mu \mathrm{m}$ layer

\subsection{Laser Remelting}

The tests reveal that as the locally increased layer thickness increases, porosity, elongation at break and impact energy linearly decrease in the affected region. Greater layer thicknesses require more energy input for complete melting of the build material; this can be achieved by changing the build parameters. A possible solution to reduce porosity was analysed: double melting of the layers. Fig. 10 shows a CT image of the laser-sintered part containing layers with different thicknesses. The sample that contains layers melted twice by laser has less porosity.

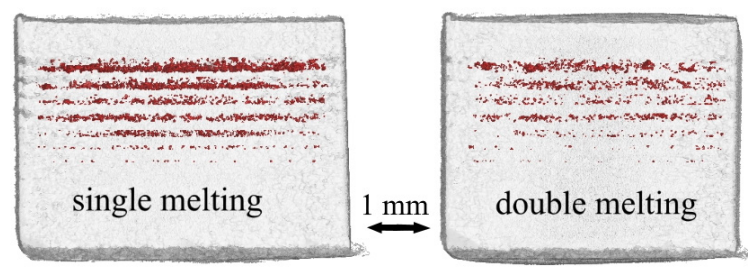

Fig. 10. 3D porosity map of single and double melted layers

Fig. 11 shows the porosity analysis of the samples. Increased thickness layers melted twice by laser have significantly less porosity than layers melted only once.

Fig. 12 shows the influence of laser re-melting on impact energy. The samples containing layers melted twice have higher impact energy. 


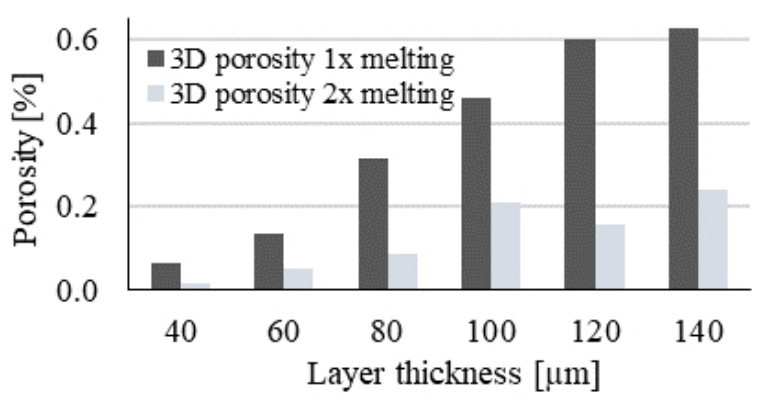

Fig. 11. Porosity as a function of layer thickness for single and double melted layers

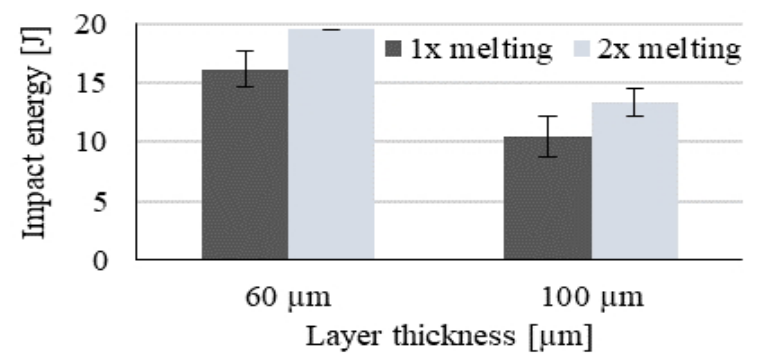

Fig. 12. Impact energy as a function of layer thickness for single and double melted layers

\section{CONCLUSIONS}

The production process occasionally needs to be interrupted due to lens cleaning, powder refilling, or technical problems. Process restarting, different heights of hybrid parts, or building plate movements due to recoater collisions may cause a thicker layer being built.

It was found that an increase in layer thickness decreases elongation at break in a linear fashion, while strength values are not affected when the layer thickness melted in one step lower than $160 \mu \mathrm{m}$. Energy absorbed by the specimens during impact testing and layer thickness shows a similar linear behaviour as elongation at break.

A possible way of reducing porosity by melting the layers twice was analysed. The sample that contains layers melted twice by laser has less porosity and higher impact energy.

\section{ACKNOWLEDGEMENTS}

The research presented in this paper was supported by the ÚNKP-19-3-III-SZE-9 New National Excellence Program of the Ministry for Innovation and Technology and EFOP 3.6.1-16-2016-00017, and it was carried out as part of the EFOP-3.6.2-16-201700016 project.

\section{REFERENCES}

[1] Gu, D.D., Meiners, W., Wissenbach, K., Poprawe, R. (2012). Laser additive manufacturing of metallic components: materials, processes and mechanisms. International Materials Reviews, vol. 57, no. 3, p. 133-164, D0l:10.1179/174328041 1y.0000000014.

[2] Manfredi, D., Calignano, F., Ambrosio, E.P., Krishnan, M., Canali, R., Biamino, S., Pavese, M., Atzeni, E., Iuliano, L., Fino, P., Badini, C. (2013). Direct metal laser sintering: An additive manufacturing technology ready to produce lightweight structural parts for robotic applications. La Metallurgia Italiana, vol. 10, p. 15-24.

[3] Jeon, T.J., Hwang, T.W., Yun, H.J., VanTyne, C.J., Moon, Y.H. (2018). Control of porosity in parts produced by a direct laser melting process. Applied Sciences, vol. 8, no. 12, p. 25732588, DOI:10.3390/app8122573.

[4] Pisula, J. M., Budzik, G., Przeszlowski, L. (2018). An analysis of the surface geometric structure and geometric accuracy of cylindrical gear teeth manufactured with the direct metal laser sintering (DMLS) method. Strojniški vestnik Journal of Mechanical Engineering, vol. 65, no. 2, p. 78-86, DOl:10.5545/sv-jme.2018.5614.

[5] Dolinšek, S., Panjan, P., Syvanen, T., Ramovš, J. (2006). Lasersintered tools for the die-casting of aluminum. Strojniški vestnik - Journal of Mechanical Engineering, vol. 52, no. 11, p. $738-751$.

[6] Moletsane, M.G., Krakhmalev, P., Kazantseva, N., Du Plessis, A., Yadroitsava, I., Yadroitsev, I. (2016). Tensile properties and microstructure of direct metal laser-sintered Ti6Al4V (ELI) alloy. South African Journal of Industrial Engineering, vol. 27, no. 3, p. 110-121, D0l:10.7166/27-3-1667.

[7] Grünberger, T., Domröse, R. (2015). Direct metal laser sintering: Identification of process phenomena by optical inprocess monitoring. Laser Technik Journal, vol. 12, no. 1, p. 45-48, D0I:10.1002/latj.201500007.

[8] Kasperovich, G., Haubrich, J., Gussone, J., Requena, G. (2016). Correlation between porosity and processing parameters in TiAl6V4 produced by selective laser melting. Materials and Design, vol. 105, p. 160-170, D0l:10.1016/j. matdes.2016.05.070.

[9] Keresztes, Z., Pammer, D., Szabo, P.J. (2019). EBSD Examination of Argon Ion Bombarded Ti-6Al-4V Samples Produced with DMLS Technology. Periodica Polytechnica Mechanical Engineering, vol. 63, no. 3, p. 195-200, Dol:10.3311/PPme.13821.

[10] Clijsters, S., Craeghs, T., Buls, S., Kempen, K., Kruth, J-P. (2014). In situ quality control of the selective laser melting process using a high-speed, real-time melt pool monitoring system. The International Journal of Advanced Manufacturing Technology, vol. 75, no. 5-8, p. 1089-1101, D0l:10.1007/ s00170-014-6214-8.

[11] Guan, K., Wang, Z., Gao, M., Li, X., Zeng, X. (2013). Effects of processing parameters on tensile properties of selective laser melted 304 stainless steel. Materials and Design, vol. 50, p. 581-586, D0I:10.1016/j.matdes.2013.03.056.

[12] Abd-Elghany, K., Bourell, D.L. (2012). Property evaluation of $304 \mathrm{~L}$ stainless steel fabricated by selective laser melting. 
Rapid Prototyping Journal, vol. 18, no. 5, p. 420-428, DOI:10.1108/13552541211250418.

[13] Yasa, E., Kempen, K., Kruth, J-P., Thijs, L., Van Humbeeck J. (2010). Microstructure and mechanical properties of maraging steel 300 after selective laser melting. Solid Freefrom Fabrication Symposium Proceedings, p. 383-396.

[14] Mireles, J., Ridwan, S., Morton, P.A., Hinojos, A., Wicker, R.B. (2015). Analysis and correction of defects within parts fabricated using powder bed fusion technolog. Surface Topography: Metrology and Properties, vol. 3, no. 3, p. 1-8, DOI:10.1088/2051-672X/3/3/034002.

[15] Gong, H., Rafi, K., Gu, H., Starr, T., Stucker, B. (2014). Analysis of defect generation in Ti-6Al-4V parts made using powder bed fusion additive manufacturing processes. Additive Manufacturing, vol. 1-4, p. 87-98, D0l:10.1016/j. addma.2014.08.002.

[16] Thijs, L Verhaeghe, F., Craeghs, T., Humbeeck, J. V., Kruth, J.-P. (2010). A study of the microstructural evolution during selective laser melting of Ti-6Al-4V. Acta Materialia, vol. 58, no. 9, p. 3303-3312, D0l:10.1016/j.actamat.2010.02.004.

[17] Maskery, I., Aboulkhair, N.T., Corfield, M.R., Tuck, C., Clare, A.T., Leach, R.K., Hague, R.J. M. (2015). Quantification and characterisation of porosity in selectively laser melted Al-Si10-Mg using X-ray computed tomography. Materials Characterization, vol. 111, p. 193-204, D0l:10.1016/j. matchar.2015.12.001.
[18] Yi, H., Qi, L., Luo, J., Zhang, D., Li, N. (2019). Direct fabrication of metal tubes with high-quality inner surfaces via droplet deposition over soluble cores. Journal of Materials Processing Technology, vol. 264, p. 145-154, D0l:10.1016/j. jmatprotec.2018.09.004.

[19] Wits, W.W., Carmignato, S., Zanini, F., Vaneker, T.H.J. (2016). Porosity testing methods for the quality assessment of selective laser melted parts. CIRP Annals, vol. 65, no. 1, p. 201-204, DOl:10.1016/j.cirp.2016.04.054.

[20] Hatos, I., Fekete, I., Ibriksz, T., Kocsis, B., Nagy, A. L., Hargitai, H. (2018). Effect of locally increased melted layer thickness on the mechanical properties of laser sintered tool steel parts. IOP Conference Series: Materials Science and Engineering, vol. 426, p. 012014-012019, D0l:10.1088/1757899X/426/1/012014.

[21] MSZ EN ISO 6892-1:2016 Standard: Metallic materials. Tensile testing. Part 1: Method of test at room temperature, International Organization for Standardization, Geneve.

[22] MSZ EN ISO 148-1:2017 Standard: Metallic materials. Charpy pendulum impact test. Part 1: Test method. International Organization for Standardization, Geneve.

[23] Hardin, R.A., Beckermann, C. (2013). Effect of porosity on deformation, damage, and fracture of cast steel. Metallurgical and Materials Transactions A, vol. 44, p. 5316-5332, DOI:10.1007/s11661-013-1669-z. 